Check for updates

Cite this: RSC Adv., 2019, 9, 33229

Received 12th August 2019

Accepted 29th September 2019

DOI: $10.1039 / c 9 r a 06256 d$

rsc.li/rsc-advances

\title{
Optimizing sandwich-structured composites based on the structure of the filler and the polymer matrix: toward high energy storage properties
}

\author{
Yang Cui, ${ }^{\text {ab }}$ Xuan Wang, ${ }^{\text {ab }}$ Tiandong Zhang, (D) *ab Changhai Zhang (D) ab \\ and Qingguo Chi (iD *ab
}

\begin{abstract}
Polymer-based energy storage materials have been widely applied in the energy storage industry, such as in the hybrid electric vehicle and power-conditioning equipment, due to their moderate energy density and ultrafast charging/discharging speed. Accordingly, the improvement of the energy storage density of polymer matrix composites has become the focus of current research. In this study, different fillers (e.g., $0.5 \mathrm{Ba}\left(\mathrm{Zr}_{0.2} \mathrm{Ti}_{0.8}\right) \mathrm{O}_{3}-0.5\left(\mathrm{Ba}_{0.7} \mathrm{Ca}_{0.3}\right) \mathrm{TiO}_{3}$ nanofibers (BCZT NFs), BCZT + Ag NFs and BCZT + Ag@Al $\mathrm{O}_{3}$ NFs) were synthesized via electrospinning and were added to the poly(vinylidene fluoride) (PVDF) matrix as a middle layer in sandwich-structure composites. The PVDF polymer-containing PMMA was prepared as the outer layer in the sandwich structure composites. These sandwich-structured composites have low loss, low current density, better breakdown strength and higher efficiency. In particular, 40\% PMMA/ $\mathrm{PVDF} / 3 \mathrm{vol} \% \mathrm{BCZT}+\mathrm{Ag}_{\mathrm{AAl}} \mathrm{O}_{3} / \mathrm{PVDF} / 40 \%$ PMMA/PVDF composites have an energy density of $7.23 \mathrm{~J}$ $\mathrm{cm}^{-3}$ and efficiency above $75.8 \%$ at $370 \mathrm{kV} \mathrm{mm}^{-1}$. This article could open up a convenient and effective means for the practical application of power-pulsed capacitors by tuning the filler nanostructure and polymer nanocomposites.
\end{abstract}

\section{Introduction}

As potential energy storage materials, compared with the batteries, polymer-based dielectric energy storage materials have the advantages of high power density, fast charge and discharge speeds, no chemical reaction and so on; however, they have the problems of relatively low energy storage density. ${ }^{1-3}$ For nonlinear materials, the energy density $(U)$ can be obtained by integrating the absolute area of the electric field $(E)$ and the electric displacement $(D)$ curve. ${ }^{4,5}$ Improving the energy storage density of composites can be studied from the aspects of increasing its dielectric constant and breakdown strength. Compared with ceramic dielectric materials, polymers have higher breakdown strength, lower dielectric loss and better mechanical properties, but their dielectric constant is often lower $(\varepsilon=2-10)$, which restricts their application. ${ }^{6-8}$ To obtain higher energy density, preparing polymer-based composites is an effective method.

Early researchers focused on improving the dielectric constant of composites. However, with the progress in the research, they found that a large number of fillers must be

${ }^{a}$ Key Laboratory of Engineering Dielectrics and Its Application, Ministry of Education, Harbin University of Science and Technology, Harbin 150080, PR China. E-mail: tdzhang@hrbust.edu.cn; qgchi@hotmail.com; Fax: +86-451-86391681

${ }^{b}$ School of Electrical and Electronic Engineering, Harbin University of Science and Technology, Harbin 150080, PR China incorporated in the polymer matrix to obtain composites with higher dielectric constant, which would inevitably lead to the decrease in the breakdown strength of the composites.9-11 Therefore, researchers began to study how to obtain high dielectric composites with low filler content. Various research schemes have been proposed to reduce the content of fillers, such as using filler phases of different shapes, using different combinations of inorganic fillers, and surface modification. ${ }^{\mathbf{1 2 - 1 5}}$ It is noteworthy that the addition of metal or metal oxides can effectively improve the dielectric constant of composites. To prevent the high dielectric loss and leakage current of the composites caused by the contact between metals or metal oxides, the metal or metal oxides are compounded with the insulating fillers and then filled into the polymer matrix. For example, BT particles with Ag were added to the PVDF matrix. The results showed that the dielectric constant of the $43.4 \mathrm{vol} \%$ BT-Ag/PVDF composite was 94.3 and the dielectric loss was 0.06 at $1 \mathrm{kHz} .{ }^{14}$ However, if the breakdown strength of the composites cannot be improved, the energy density of the composites cannot be significantly increased. It has been proved that under the same conditions, the composites with one-dimensional (1D) fillers have higher dielectric constant and breakdown strength than the composites with zero-dimensional (0D) fillers. This is because 1D fillers have larger aspect ratios that enhance the dielectric constant of composites as well as smaller specific surface area, which are conducive to decreasing the surface energy and promoting the filler dispersion in the polymer 
matrix. ${ }^{4,6,16-18}$ For example, compared with the composites filled with BT particles, the composites filled with BT nanofibers have higher breakdown strength $\left(E_{\mathrm{b}}=370 \mathrm{MV} \mathrm{m}^{-1}\right)$ and higher energy density $\left(U=8.78 \mathrm{~J} \mathrm{~cm}^{-3}\right) .{ }^{6}$ Besides, another effective approach to improve breakdown strength is to incorporate a lower dielectric constant shell layer to alleviate the dielectric difference between fillers with high dielectric constant and polymer matrices with low dielectric constant. The large dielectric difference will lead to a higher non-uniform electric field in composites. ${ }^{2,18-22}$ For example, the introduction of an $\mathrm{Al}_{2} \mathrm{O}_{3}$ insulating layer between $\mathrm{BT}$ and PVDF improved the breakdown property and energy density of the $\mathrm{BaTiO}_{3} @ \mathrm{Al}_{2} \mathrm{O}_{3}$ NFs/PVDF composites $\left(E_{\mathrm{b}}=420 \mathrm{MV} \mathrm{m}{ }^{-1}, U=10.58 \mathrm{~J} \mathrm{~cm}^{-3}\right) .{ }^{18}$

In order to further improve the energy density of composites, the multilayer structure is proposed. This structure is generally divided into a high dielectric layer to enhance the strong polarization and a high breakdown layer to ensure the breakdown strength of the composite. ${ }^{23-25} \mathrm{Hu}$ used BT NF-filled composites as the middle layer and BT NPs as the outer layer. The results show that the BT NF layer improved the breakdown strength of the composites, and the composites had higher energy density at higher field strength $\left(E_{\mathrm{b}}=453 \mathrm{MV} \mathrm{m}^{-1}, U=\right.$ $\left.9.72 \mathrm{~J} \mathrm{~cm}^{-3}\right) .{ }^{24}$

In addition to energy storage density, charge-discharge efficiency is also an important parameter to be considered. In the field of capacitor applications, the energy that cannot be released will be released in the form of Joule heat. If the efficiency of energy storage materials is too low, it will not only cause a waste of energy but also cause damage to devices because of excessive Joule heat. ${ }^{26}$

In this paper, we prepared a composite fiber consisting of $0.5 \mathrm{Ba}\left(\mathrm{Zr}_{0.2} \mathrm{Ti}_{0.8}\right) \mathrm{O}_{3}-0.5\left(\mathrm{Ba}_{0.7} \mathrm{Ca}_{0.3}\right) \mathrm{TiO}_{3}(\mathrm{BCZT})$ with high dielectric constant and metallic $\mathrm{Ag}(\mathrm{BCZT}+\mathrm{Ag})$. On this basis, the $\mathrm{Al}_{2} \mathrm{O}_{3}$ shell layer was coated on the $\mathrm{BCZT}+\mathrm{Ag}$ fiber by coaxial spinning technology (BCZT + $\left.\mathrm{Ag} @ \mathrm{Al}_{2} \mathrm{O}_{3}\right)$. The ferroelectric polyvinylidene fluoride (PVDF) was chosen as the matrix to prepare the composite films. In order to improve the breakdown field strength and reduce the loss of PVDF polymer, PVDF was blended with linear dielectric polymethyl methacrylate (PMMA). The composite films and blended polymer films were respectively studied. After determining their advantages, composite films and blended polymer films were compounded by the sandwich structure, and sandwich structure composites with better energy storage performance were obtained.

\section{Experimental}

\subsection{Materials}

PVDF was supplied by Shanghai 3F New Materials Technology Co. Ltd. PMMA, $\mathrm{Al}\left(\mathrm{NO}_{3}\right)_{3} \cdot 9 \mathrm{H}_{2} \mathrm{O}, \mathrm{Ba}(\mathrm{OH})_{2} \cdot 8 \mathrm{H}_{2} \mathrm{O}, \mathrm{Ca}(\mathrm{OH})_{2}$, $\mathrm{C}_{16} \mathrm{H}_{36} \mathrm{O}_{4} \mathrm{Ti}, \mathrm{AgNO}_{3}$, ammonium hydroxide $\left(\mathrm{NH}_{3} \cdot \mathrm{H}_{2} \mathrm{O}\right)$, hydrazine hydrate $\left(\mathrm{N}_{2} \mathrm{H}_{4} \cdot \mathrm{H}_{2} \mathrm{O}\right)$, ethanol $\left(\mathrm{C}_{2} \mathrm{H}_{6} \mathrm{O}\right)$, acetic acid $\left(\mathrm{CH}_{3}\right.$ $\mathrm{COOH})$, acetylacetone $\left(\mathrm{C}_{5} \mathrm{H}_{8} \mathrm{O}_{2}\right)$, and $\mathrm{N}, \mathrm{N}$-dimethylformamide (DMF) were purchased from Sinopharm Chemical Reagent Co. Ltd. HCl was purchased from Tianjin Zhiyuan Chemical Reagent Co. Ltd. $\mathrm{C}_{20} \mathrm{H}_{28} \mathrm{O}_{8} \mathrm{Zr}$, polyvinylpyrrolidone (PVP, K90), and tris(hydroxymethyl)aminomethane (tris) were purchased from Aladdin.

\subsection{Preparation of inorganic fillers}

The $0.5 \mathrm{Ba}\left(\mathrm{Zr}_{0.2} \mathrm{Ti}_{0.8}\right) \mathrm{O}_{3}-0.5\left(\mathrm{Ba}_{0.7} \mathrm{Ca}_{0.3}\right) \mathrm{TiO}_{3}$ nanofibers (BCZT NFs) were synthesized by the electrospinning technology. The specific method is based on previous experimental steps. ${ }^{27} \mathrm{~A}$ solution containing $7.6 \mathrm{~mL}$ ethanol, $18.1 \mathrm{~mL}$ acetic acid and $3.08 \mathrm{~mL}$ acetylacetone was prepared, and $4.344 \mathrm{~g} \mathrm{Ba}(\mathrm{OH})_{2}$ $\cdot 8 \mathrm{H}_{2} \mathrm{O}, 0.18 \mathrm{~g} \mathrm{Ca}(\mathrm{OH})_{2}$ and $0.788 \mathrm{~g} \mathrm{C}_{20} \mathrm{H}_{28} \mathrm{O}_{8} \mathrm{Zr}$ were dissolved in this solution. After the solution was completely clarified, $4.95 \mathrm{~mL} \mathrm{C}_{16} \mathrm{H}_{36} \mathrm{O}_{4} \mathrm{Ti}$ was dripped into the solution and then, a homogeneous solution was obtained by further stirring. PVP $(1.4 \mathrm{~g})$ was added to the solution under stirring for $12 \mathrm{~h}$, and the BCZT precursor was obtained. A certain amount of spinning precursor was placed in the injecting device, and $15 \mathrm{kV}$ voltage was applied for electrospinning. The electrospun fiber was calcined at $700{ }^{\circ} \mathrm{C}$ for $3 \mathrm{~h}$ to obtain the BCZT fiber.

$\mathrm{BCZT}+\mathrm{Ag}$ nanofibers were then prepared via electrospinning technology. The $\mathrm{Ag}$ particles had been prepared according to an existing method. ${ }^{28}$ Briefly, $6 \mathrm{~mL} \mathrm{NH}{ }_{3} \cdot \mathrm{H}_{2} \mathrm{O}$ was mixed with $10 \mathrm{~mL}$ deionized water. Then, $3 \mathrm{~g} \mathrm{AgNO}$ was added to the above solution under stirring to produce solution A. Next, $1.8 \mathrm{~mL} \mathrm{~N} \mathrm{H}_{4} \cdot \mathrm{H}_{2} \mathrm{O}$ was mixed with $10 \mathrm{~mL}$ ethanol to get solution B. Further, $1.2 \mathrm{~g}$ PVP was dissolved in $70 \mathrm{~mL}$ ethanol to obtain solution C. Solutions A and B were alternately dripped into solution $\mathrm{C}$ under stirring at $1000 \mathrm{rpm}$. After both solutions A and $\mathrm{B}$ were completely dripped, the mixture was stirred for $30 \mathrm{~min}$. The solution was dried at $80{ }^{\circ} \mathrm{C}$ for $12 \mathrm{~h}$ and then calcined at $300{ }^{\circ} \mathrm{C}$ for $4 \mathrm{~h}$. Finally, $\mathrm{Ag}$ particles were obtained after grinding. The obtained $\mathrm{Ag}$ particles were placed into the BCZT spinning precursors (precursor preparation method reference BCZT NFs). The mass ratio of Ag to BCZT was $1: 4$. The sintering temperature was consistent with that of BCZT NFs.

$\mathrm{BCZT}+\mathrm{Ag} @ \mathrm{Al}_{2} \mathrm{O}_{3}$ nanofibers were obtained by coaxial spinning technology. The core layer is BCZT $+\mathrm{Ag}$ and the shell layer is $\mathrm{Al}_{2} \mathrm{O}_{3}$. The preparation method of the core layer BCZT + $\mathrm{Ag}$ precursor is similar to that of BCZT $+\mathrm{Ag}$ nanofibers, but the content of PVP in the precursor decreases from $0.53 \mathrm{~g}$ to $0.25 \mathrm{~g}$. In the preparation of the shell layer $\mathrm{Al}_{2} \mathrm{O}_{3}, 0.2 \mathrm{~g} \mathrm{Al}\left(\mathrm{NO}_{3}\right)_{3}$ was added to $2 \mathrm{~mL}$ deionized water, and $0.7 \mathrm{~g}$ PVP was dissolved in $20 \mathrm{~mL}$ ethanol. The obtained transparent $\mathrm{Al}\left(\mathrm{NO}_{3}\right)_{3}$ solution was dripped into the PVP solution under stirring. The $\mathrm{Al}_{2} \mathrm{O}_{3}$ precursor was obtained when the solution was clarified again. In the spinning process, the spinning speed of the core layer and shell layer was $1: 2$. The sintering temperature was consistent with that for BCZT NFs.

\subsection{Surface modification}

Inorganic fillers $(1 \mathrm{~g})$ were dispersed in $0.02 \mathrm{~mol} \mathrm{~L}^{-1}$ dopamine hydrochloride solutions $(200 \mathrm{~mL})$. The $\mathrm{HCl}$ was dripped into the above solution to adjust the $\mathrm{pH}$ of the solution to 8.5. Then, tris(hydroxymethyl) aminomethane $(0.4 \mathrm{~g})$ was added to the solution under stirring $12 \mathrm{~h}$. Then, the fillers were obtained by centrifugation and drying. 


\subsection{Fabrication of composite films}

PVDF and PMMA/PVDF polymer films were obtained by the coating method. PVDF was added to DMF to prepare a $0.1 \mathrm{~g}$ $\mathrm{mL}^{-1}$ solution. After PVDF was completely dissolved, the PMMA was added to the above solution at a certain rate, and stirring was continued for $12 \mathrm{~h}$. The solution was coated on clean glass and dried at $60{ }^{\circ} \mathrm{C}$ for $12 \mathrm{~h}$ to obtain PVDF, 15\% PMMA/PVDF or 40\% PMMA/PVDF polymer films.

The preparation of composite films was similar to the above process. First, the PVDF was added to DMF, and the inorganic fillers were dispersed in DMF. When PVDF was completely dissolved, the inorganic filler suspension was added to it, and the filling ratio was 3 vol\%. The solution was coated on clean glass and dried at $60{ }^{\circ} \mathrm{C}$ for $12 \mathrm{~h}$ to obtain the composite films.

Sandwich-structure composites were prepared by the hot pressing process. The composite film as the intermediate layer and the polymer films as the outer layer were smoothly stacked one by one, and the sandwich structure film was formed by hot pressing at high temperature. The hot pressing condition was $150{ }^{\circ} \mathrm{C}$ for 10 minutes. The schematic illustration of the fabrication process for sandwich-structure composites is shown in Fig. 1.

\subsection{Characterization}

The morphology of fillers and cross-sectional images of composite films were determined by scanning electron microscopy (SEM, SU 8020) and transmission electron microscopy (TEM, JEM-2010F). X-ray diffraction (XRD, Empyrean, PANalytical, Holland) was used to study the crystal structures of fillers and composites using a $\mathrm{Cu} \mathrm{K} \alpha$ source. The dielectric performance of composite films was characterized by a broadband dielectric spectrometer (Novocontrol GmbH, Germany) from frequency $10^{0}$ to $10^{7} \mathrm{~Hz}$. The $D-E$ loops and current density were characterized by a Precision LC ferroelectric test system (Radiant Technologies, USA).

\section{Results and discussion}

$\mathrm{BCZT}, \mathrm{BCZT}+\mathrm{Ag}$ and $\mathrm{BCZT}+\mathrm{Ag} @ \mathrm{Al}_{2} \mathrm{O}_{3}$ nanofibers were prepared by electrospinning and coaxial spinning. The XRD patterns of three inorganic fillers are displayed in Fig. 2a-c. In Fig. 2a, the diffraction peaks at $2 \theta=22.12^{\circ}, 31.52^{\circ}, 38.81^{\circ}$,

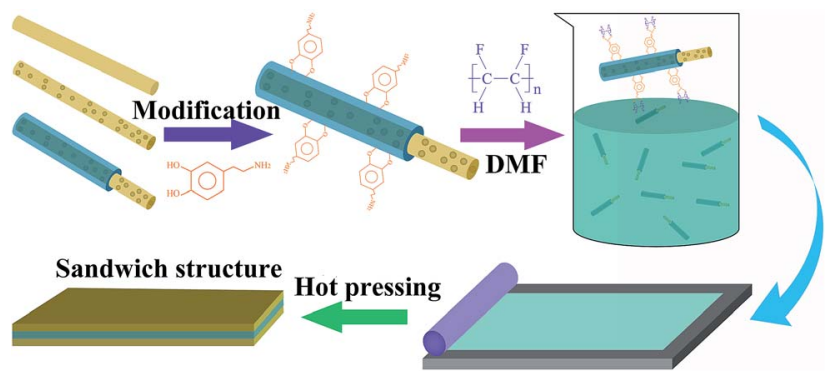

Fig. 1 Schematic of the fabrication process of sandwich structure composites. $45.17^{\circ}, 50.80^{\circ}, 56.10^{\circ}, 65.76^{\circ}, 71.42^{\circ}, 74.75^{\circ}, 79.21^{\circ}$ and $83.45^{\circ}$ can be indexed to the (100), (110), (111), (200), (210), (211), (220), (300), (310), (311) and (222) reflections of BCZT, respectively. In addition to the diffraction peaks of BCZT, the diffraction peaks of $\mathrm{Ag}$ can be seen in Fig. 2b. For BCZT + $\mathrm{Ag} @ \mathrm{Al}_{2} \mathrm{O}_{3}$, besides the diffraction peaks of BCZT and Ag, the diffraction peaks of $\mathrm{Al}_{2} \mathrm{O}_{3}$ can also be seen in Fig. 2c. In order to better prove the existence of various elements, EDS studies were performed (illustrations of Fig. 2a-c). Consistent with the XDR results, the elemental signals of $\mathrm{Ba}, \mathrm{Ca}, \mathrm{Zr}$ and $\mathrm{Ti}$ appeared in BCZT. The elemental signals of $\mathrm{Ag}$ appeared in $\mathrm{BCZT}+\mathrm{Ag}$. The elemental signals of $\mathrm{Al}$ appeared in $\mathrm{BCZT}+\mathrm{Ag} @ \mathrm{Al}_{2} \mathrm{O}_{3}$. Observation of the morphologies of BCZT, BCZT + $\mathrm{Ag}$ and $\mathrm{BCZT}+\mathrm{Ag} @ \mathrm{Al}_{2} \mathrm{O}_{3}$ indicated that they have large aspect ratios. As shown in the SEM image, BCZT and BCZT $+\mathrm{Ag}$ exhibited average diameters of about $200 \mathrm{~nm}$ (Fig. 2d and e). BCZT + $\mathrm{Ag@} \mathrm{Al}_{2} \mathrm{O}_{3}$ was synthesized via a coaxial spinning method, with a diameter of about $260 \mathrm{~nm}$ in which the outer diameter was about $30 \mathrm{~nm}$ (Fig. 2f). In order to better observe the core-shell structure of BCZT $+\mathrm{Ag} @ \mathrm{Al}_{2} \mathrm{O}_{3}$, higher magnification TEM images and elemental mappings are shown in Fig. 2g. Moreover, BCZT $+\mathrm{Ag}$ has a rougher surface compared with that of BCZT and BCZT $+\mathrm{Ag} @ \mathrm{Al}_{2} \mathrm{O}_{3}$, which is due to the addition of $\mathrm{Ag}$ particles (illustrations of Fig. 2d-f). The morphology and size of the $\mathrm{Ag}$ particles have been studied in previous study, and were reported to be $80 \mathrm{~nm}$ spherical particles. $^{29}$

Fig. 3 shows the XRD patterns of polymer and filler/PVDF composites. It can be seen that the XRD pattern of the pure PVDF and PMMA/PVDF blend polymer exhibited wide humps at $15^{\circ}-20^{\circ}$, which was a feature of PVDF and PMMA. Similarly, the diffraction peaks of the fillers and PVDF can be seen in the filler/ PVDF composites.

Fig. 4 shows the dielectric constant, dielectric loss tangent and conductivity of the polymer and filler/PVDF composites at $10 \mathrm{~Hz}$. Compared with PMMA/PVDF polymer, PVDF has the highest dielectric constant. This is attributed to the introduction of the linear polymer PMMA, which has a lower dielectric constant $(\varepsilon=3.5) \cdot{ }^{30,31}$ However, the dielectric loss tangent and conductivity of the PMMA/PVDF polymer were also reduced due to the introduction of PMMA. The filler/PVDF composites have a higher dielectric constant than the polymer because of the higher dielectric constant of ferroelectric materials contributing to the interfacial accumulation of charges. ${ }^{6}$ The BCZT $+\mathrm{Ag} /$ PVDF composites have the highest dielectric constant because the addition of $\mathrm{Ag}$ particles with good conductivity increases the charge accumulation at the interface. However, the $\mathrm{Ag}$ particles caused the BCZT $+\mathrm{Ag} / \mathrm{PVDF}$ composites to have the highest dielectric loss and conductivity. Interestingly, the dielectric constant of BCZT $+\mathrm{Ag} @ \mathrm{Al}_{2} \mathrm{O}_{3} / \mathrm{PVDF}$ is lower than that of the other two composites. This is because (i) the addition of the $\mathrm{Al}_{2} \mathrm{O}_{3}$ shell reduces the polarization of the interface ${ }^{32}$ and (ii) $\mathrm{Al}_{2} \mathrm{O}_{3}$ as an insulating layer effectively inhibits the space charge transport between fillers and the matrix. ${ }^{33}$ Moreover, the $\mathrm{Al}_{2} \mathrm{O}_{3}$ shell layer reduces the dielectric loss and conductivity of the composites, which was confirmed by the results of Fig. $4 \mathrm{~b}$ and c. This provides favorable conditions for improving the breakdown and energy densities of the composites. These results 

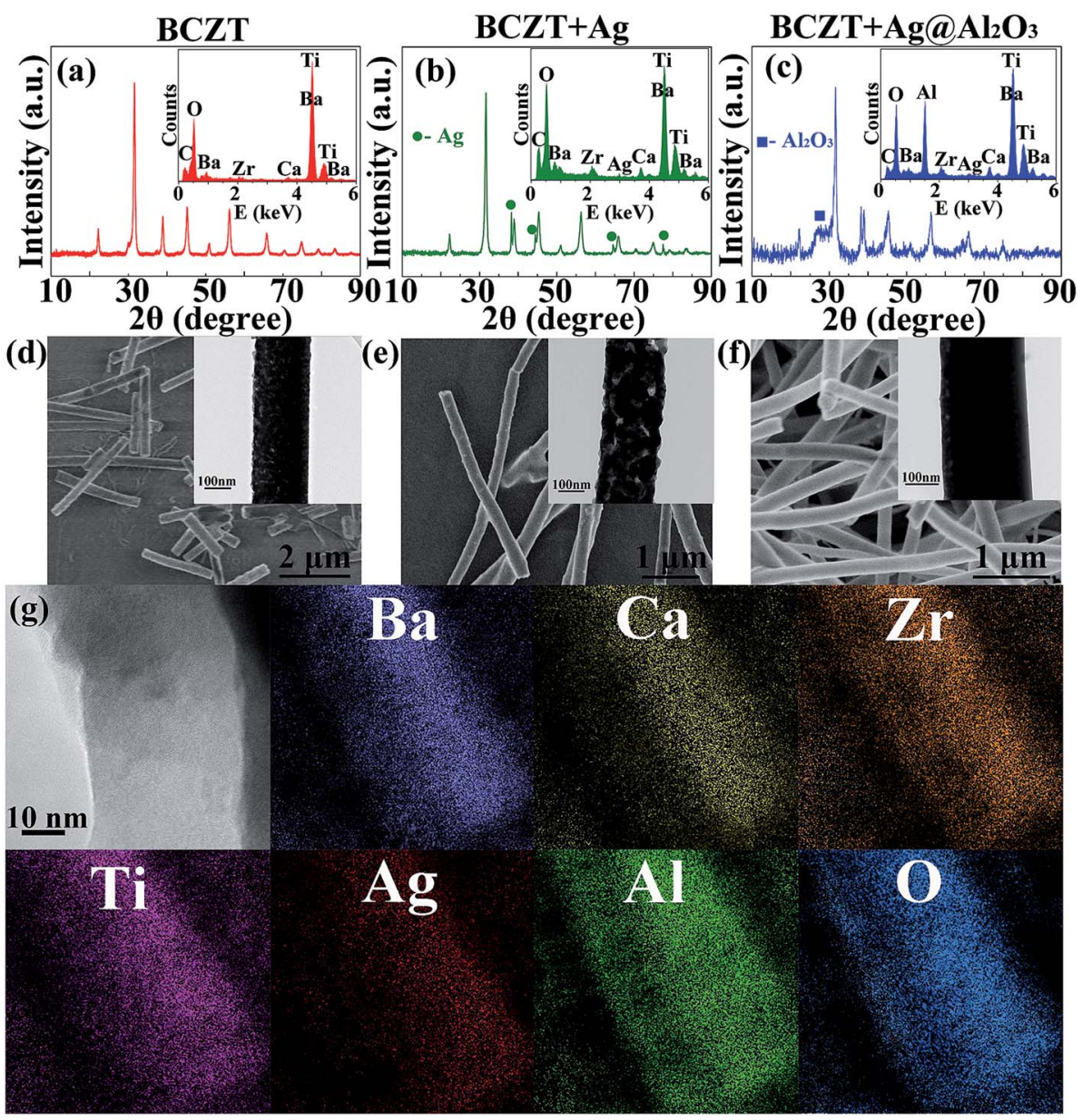

Fig. 2 XRD patterns of (a) $\mathrm{BCZT}$, (b) $\mathrm{BCZT}+\mathrm{Ag}$, (c) $\mathrm{BCZT}+\mathrm{Ag}_{\mathrm{aAl}} \mathrm{O}_{3}$, and $\mathrm{SEM}$ images of (d) $\mathrm{BCZT}$, (e) $\mathrm{BCZT}+\mathrm{Ag}$, (f) $\mathrm{BCZT}+\mathrm{Ag}\left(\mathrm{Al} \mathrm{O}_{3}\right.$. The corresponding EDS spectra are shown in the insets in (a)-(c); the corresponding TEM diagrams are given in the insets of (d) - (f). (g) The higher magnification TEM images and elemental mappings of $\mathrm{BCZT}+\mathrm{Ag}_{\mathrm{AAl}} \mathrm{O}_{3}$.

indicate that $\mathrm{BCZT}+\mathrm{Ag}$ can provide larger polarization, and $\mathrm{BCZT}+\mathrm{Ag} @ \mathrm{Al}_{2} \mathrm{O}_{3}$ can effectively reduce dielectric loss.

As shown in Fig. 5a, the current densities of the polymers were ranked in the order of PVDF $>15 \%$ PMMA/PVDF $>40 \%$ PMMA/PVDF, which indicates that the addition of PMMA of the blend polymer significantly influences the current density of their polymer. Among the composites, the BCZT $+\mathrm{Ag} @ \mathrm{Al}_{2} \mathrm{O}_{3} /$ PVDF composites exhibited the lowest current density, while BCZT + Ag/PVDF composites had the highest current density. The reason for this may be the introduction of Ag into BCZT + $\mathrm{Ag}$ that increases the current density of the composites and the rough surface of BCZT + Ag (as shown in Fig. 2e), which may lead to cavities or defects at the interface between the filler and the matrix. On the contrary, the non-crystalline $\mathrm{Al}_{2} \mathrm{O}_{3}$ shell in $\mathrm{BCZT}+\mathrm{Ag@Al} \mathrm{O}_{3}$ makes the fiber surface smooth (as shown in Fig. 2f), while the insulated $\mathrm{Al}_{2} \mathrm{O}_{3}$ shell also reduces the possibility of charge passing through the core-shell nano-filler into the polymer matrix, which reduces the current density of the composites. ${ }^{34}$ These results are also consistent with the dielectric loss tangent.

The breakdown strength plays a vital role in improving the energy density of dielectric capacitors. The characteristic

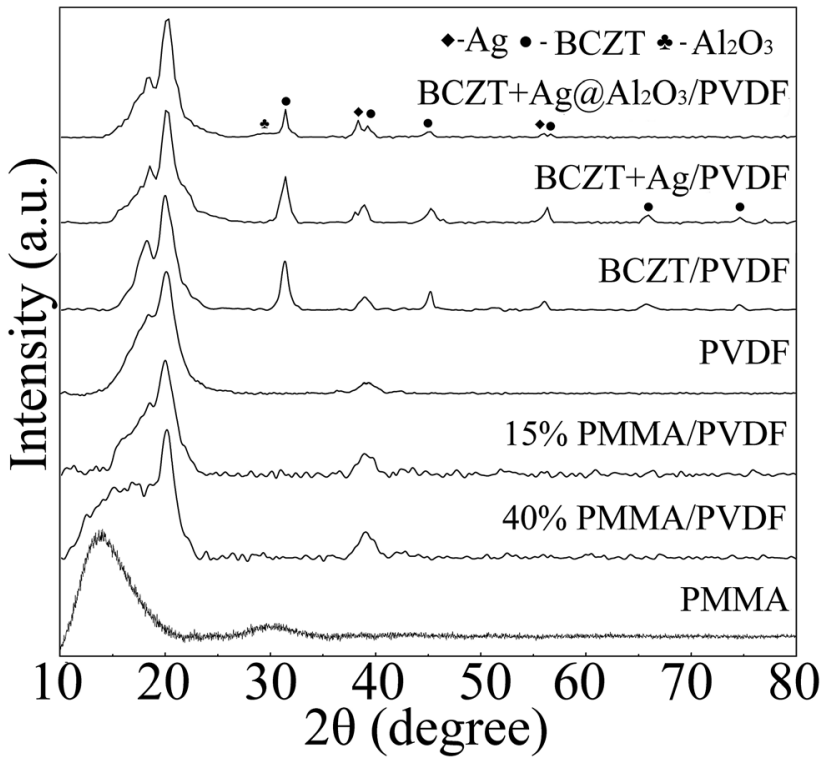

Fig. 3 XRD pattern of polymer and filler/PVDF composites. 


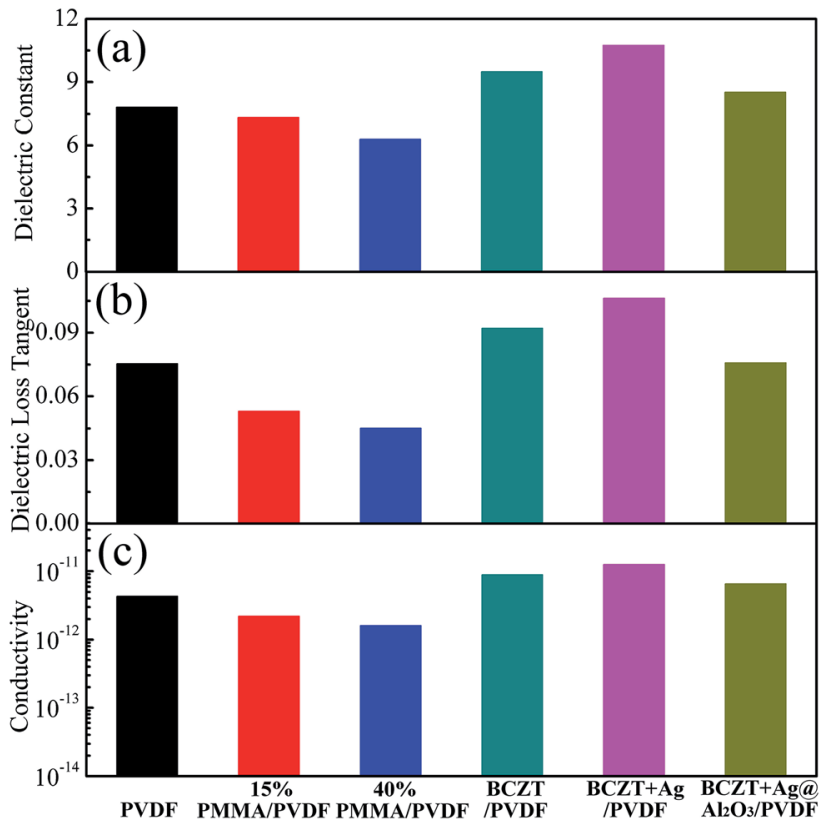

Fig. 4 Dielectric constant (a), dielectric loss tangent (b) and conductivity (c) of polymer films and composite films at $10 \mathrm{~Hz}$.

breakdown strength of the polymer and composites was analyzed using the Weibull distribution function. It can be seen from Fig. $5 \mathrm{~b}$ that the breakdown strength of the polymer was maintained at a high level $\left(350.5-399.0 \mathrm{kV} \mathrm{mm}{ }^{-1}\right)$ and the breakdown strength of the PMMA/PVDF blend polymer was higher than that of PVDF. This is because PMMA with low dielectric and linear characteristics reduces the loss, conductivity and current density of PVDF. Also, previous reports show that the addition of PMMA to PVDF can induce the phase transition from the $\alpha$ phase to $\beta$ phase or $\gamma$ phase, which is also beneficial for improving the breakdown field of the polymer film. ${ }^{30,35}$ However, the breakdown strength of the composites are lower than that of the polymer. The $\mathrm{BCZT}+\mathrm{Ag} @ \mathrm{Al}_{2} \mathrm{O}_{3} / \mathrm{PVDF}$ composite has higher breakdown strength than the other composites, while the BCZT $+\mathrm{Ag} / \mathrm{PVDF}$ has the lowest. First, due to the large dielectric difference between the high dielectric fillers and the polymer matrix, electric field distortion easily occurs at the interface, resulting in the breakdown of the composite films. The local electric field distortion can be reduced by adding a buffer-dielectric constant $\mathrm{Al}_{2} \mathrm{O}_{3}$ interface between BCZT + $\mathrm{Ag}$ and PVDF. ${ }^{6}$ Second, as mentioned above, $\mathrm{Al}_{2} \mathrm{O}_{3}$ as an insulating layer can limit the carrier migration in the interface between BCZT + Ag and the PVDF matrix, thus reducing the loss and current density of the composite films. ${ }^{33}$

The hysteresis loops show the dielectric properties at high applied fields. ${ }^{6}$ The maximum displacement $\left(D_{\max }\right)$ and remnant displacement $\left(D_{\mathrm{r}}\right)$ can be obtained by the displacement $(D)$-electric field $(E)$ curve, and the corresponding energy density and efficiency can be obtained by eqn (1) and eqn (2) as follows:

$$
\begin{gathered}
U=\int E \mathrm{~d} D \\
\eta=\frac{U}{U+U_{\text {loss }}}
\end{gathered}
$$

where $U$ is the discharge energy density, $U_{\text {loss }}$ is the loss energy density, and $\eta$ is the efficiency. As shown in Fig. 5c, the PVDF shows the higher $D_{\max }$ and $D_{\mathrm{r}}$ as compared to PMMA/PVDF under the same electric field. However, PVDF has the highest energy density and the lowest efficiency, ascribed to the highest $D_{\max }$ and $D_{\mathrm{r}}$. On the contrary, PMMA/PVDF has better efficiency
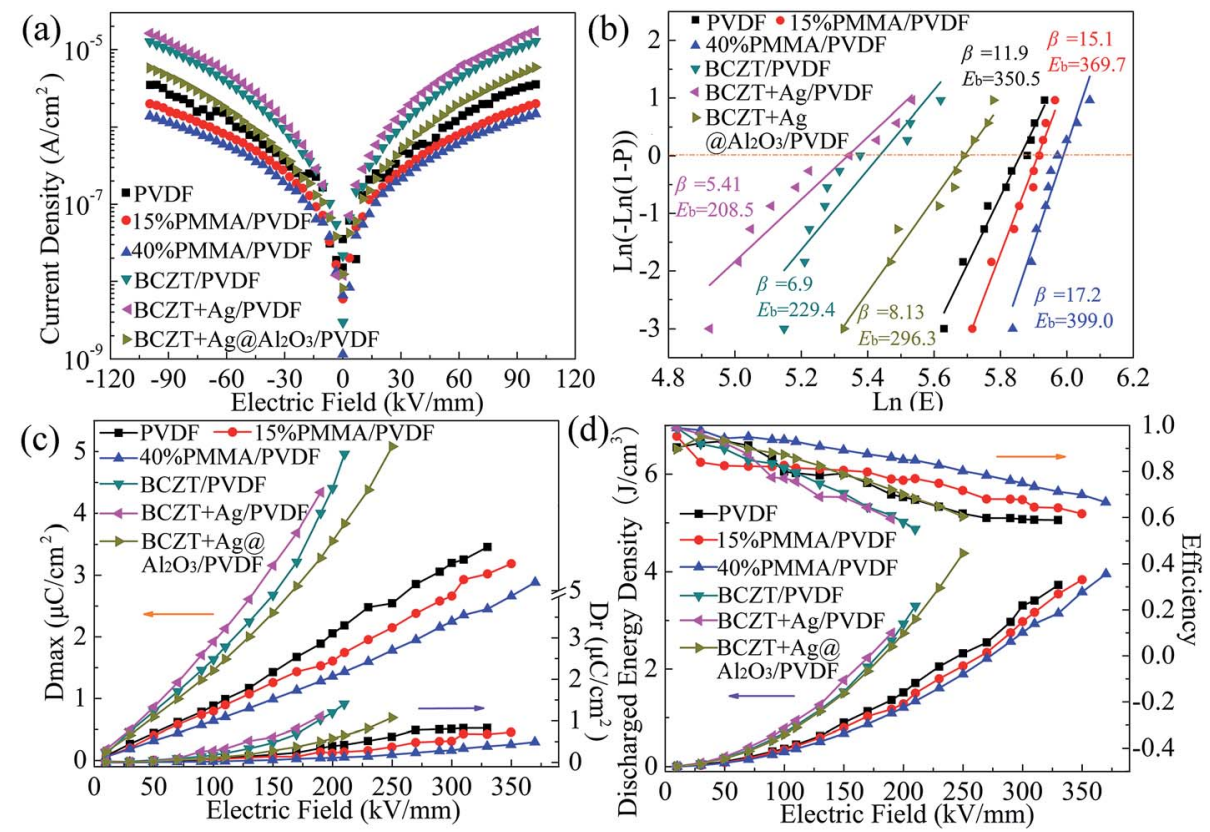

Fig. 5 Current density (a), Weibull distribution (b), maximum polarization $\left(D_{\max }\right)$ and remnant polarization $\left(D_{\mathrm{r}}\right)$ (c), energy density and efficiency (d) of polymer films and composite films. 
and energy density, especially 40\% PMMA/PVDF $(E=370 \mathrm{kV}$ $\left.\mathrm{mm}^{-1}, U=3.99 \mathrm{~J} \mathrm{~cm}^{-3}, \eta=66.4 \%\right)$. At the same electric field, the $D_{\max }$ of the three composites is higher than that of the polymer. BCZT $+\mathrm{Ag} / \mathrm{PVDF}$ exhibits the highest $D_{\max }$ and BCZT + $\mathrm{Ag} @ \mathrm{Al}_{2} \mathrm{O}_{3} / \mathrm{PVDF}$ has the lowest $D_{\max }$, while BCZT $+\mathrm{Ag} @ \mathrm{Al}_{2} \mathrm{O}_{3} /$ PVDF has the lowest $D_{\mathrm{r}}$, which will endow BCZT + $\mathrm{Ag} @ \mathrm{Al}_{2} \mathrm{O}_{3} /$ PVDF with better efficiency. It can be seen from Fig. $5 \mathrm{~d}$ that the BCZT + Ag/PVDF composite has the highest energy density at the same electric field; the BCZT + $\mathrm{Ag} @ \mathrm{Al}_{2} \mathrm{O}_{3} / \mathrm{PVDF}$ composite has the largest energy density at a higher electric field $(E=250$ $\mathrm{kV} \mathrm{mm}{ }^{-1}, U=4.38 \mathrm{~J} \mathrm{~cm}^{-3}$ ) and due to the introduction of the $\mathrm{Al}_{2} \mathrm{O}_{3}$ shell, it has the highest efficiency $(\eta=60.4 \%)$ among the three composites.

It can be seen from the above results that the polymer, especially with the addition of PMMA, has the advantages of high breakdown strength and efficiency, but also has the disadvantages of low dielectric constant and energy density. However, the composites have the advantages of high dielectric constant and energy density under the same electric field but have the disadvantages of low breakdown strength and efficiency. Although the breakdown strength and efficiency of the composites are improved by modifying fillers (as BCZT + $\mathrm{Ag} @ \mathrm{Al}_{2} \mathrm{O}_{3}$ ), they are still not as good as the polymer. In other words, a separate pursuit of high breakdown strength or high polarization of energy storage materials cannot achieve high energy storage composites. Sandwich-structured composites can combine the advantages of each layer, and adjust the electric field distribution in composites because of the dielectric properties of the composites in each layer. In this study, in order to obtain composites with higher energy density, the PVDF-based composites (BCZT + Ag/PVDF and BCZT + $\mathrm{Ag} @ \mathrm{Al}_{2} \mathrm{O}_{3} / \mathrm{PVDF}$ ) with high dielectric constant were chosen as the middle layers of the sandwich-structure composites, and the polymer with high breakdown was chosen as the outer layer. The PVDF/BCZT + Ag/PVDF/PVDF (defined as 0-32-0), 15\% PMMA/PVDF/BCZT + Ag/PVDF/15\% PMMA/PVDF (defined as 15-32-15), 40\% PMMA/PVDF/BCZT + Ag/PVDF/40\% PMMA/ PVDF (defined as 40-32-40), $\mathrm{PVDF} / \mathrm{BCZT}+\mathrm{Ag} @ \mathrm{Al}_{2} \mathrm{O}_{3} / \mathrm{PVDF} /$ PVDF (defined as 0-33-0), 15\% PMMA/PVDF/BCZT + $\mathrm{Ag} @ \mathrm{Al}_{2} \mathrm{O}_{3} / \mathrm{PVDF} / 15 \%$ PMMA/PVDF (defined as 15-33-15), 40\% PMMA/PVDF/BCZT $+\mathrm{Ag@} \mathrm{Al}_{2} \mathrm{O}_{3} / \mathrm{PVDF} / 40 \% \quad \mathrm{PMMA} / \mathrm{PVDF}$ (defined as 40-33-40) sandwich-structure composites were prepared.

Fig. 6 shows the dielectric properties of the sandwichstructure composites. When the middle layer is the same, the polymer as the outer layer plays an important role in the dielectric properties of the composites. Fig. 6a shows that the dielectric constant of the sandwich structure composite decreases as the content of PMMA increases in the polymer outer layers, as expected. However, when the same polymer is selected as the outer layer, the dielectric properties of the composites as the middle layer affect the sandwich structure composites. Therefore, the composites with BCZT + Ag/PVDF as the middle layer have a higher dielectric constant than that with $\mathrm{BCZT}+\mathrm{Ag} @ \mathrm{Al}_{2} \mathrm{O}_{3} / \mathrm{PVDF}$ as the middle layer, which is consistent with the law of dielectric constants of single-layer composites. It is noteworthy that the dielectric constant of the sandwich

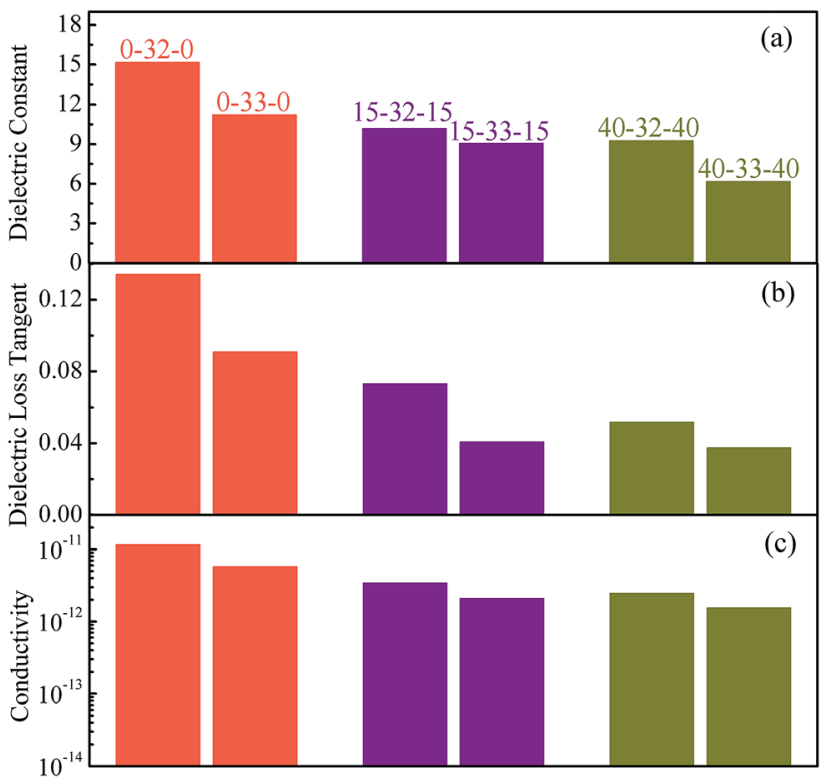

Fig. 6 Dielectric constant (a), dielectric loss tangent (b) and conductivity (c) of composite films with the sandwich structure at $10 \mathrm{~Hz}$.

composites is slightly higher than that of single-layer structures, which may be because in sandwich structures, charges are stored at the interface of two heterogeneous films. Thus, the dielectric of the sandwich-structure composites is improved. ${ }^{36,37}$ Fig. $6 \mathrm{~b}$ and $\mathrm{c}$ show the dielectric loss and conductivity of the sandwich structure composites, respectively. Consistent with the law of dielectric constant, the composites with PVDF as the outer layer have the highest dielectric loss and conductivity in the same middle layer, and the composites with BCZT + Ag/ PVDF as the middle layer have higher dielectric loss and conductivity than that with BCZT + Ag@ $\mathrm{Al}_{2} \mathrm{O}_{3} / \mathrm{PVDF}$. In particular, the use of the $40 \%$ PMMA/PVDF polymer as the outer layer or the selection of $\mathrm{BCZT}+\mathrm{Ag} @ \mathrm{Al}_{2} \mathrm{O}_{3}$ as the filler in the middle layer can be more effective at reducing the loss of the composite, which is advantageous for the breakdown of the composite and the improvement of the energy storage performance.

For the sandwich structure composites, the cross-sectional SEM microscopy, current density and breakdown properties are shown in Fig. 7. The thickness ratio between layers of sandwich structure composites is about $1: 1: 1$, which can be found from the cross-sectional SEM microscopy of 40-32-40 and 40-33-40 given in Fig. 7a and b. The current density of the sandwich structure composites is lower than that of the corresponding middle layer composites, which occurs because the polymer as the outer layer has lower current density and hinders the movement of the free electrons of the middle layer throughout the sandwich structure. When the middle layer composites are the same, the current density of the $40 \%$ PMMA/ PVDF as the outer layer sandwich-structure composite is the lowest. When the outer layer polymer selection is consistent, the current density of the composites with BCZT $+\mathrm{Ag} / \mathrm{PVDF}$ as the middle layer is higher than that with $\mathrm{BCZT}+\mathrm{Ag} @ \mathrm{Al}_{2} \mathrm{O}_{3} / \mathrm{PVDF}$ as 

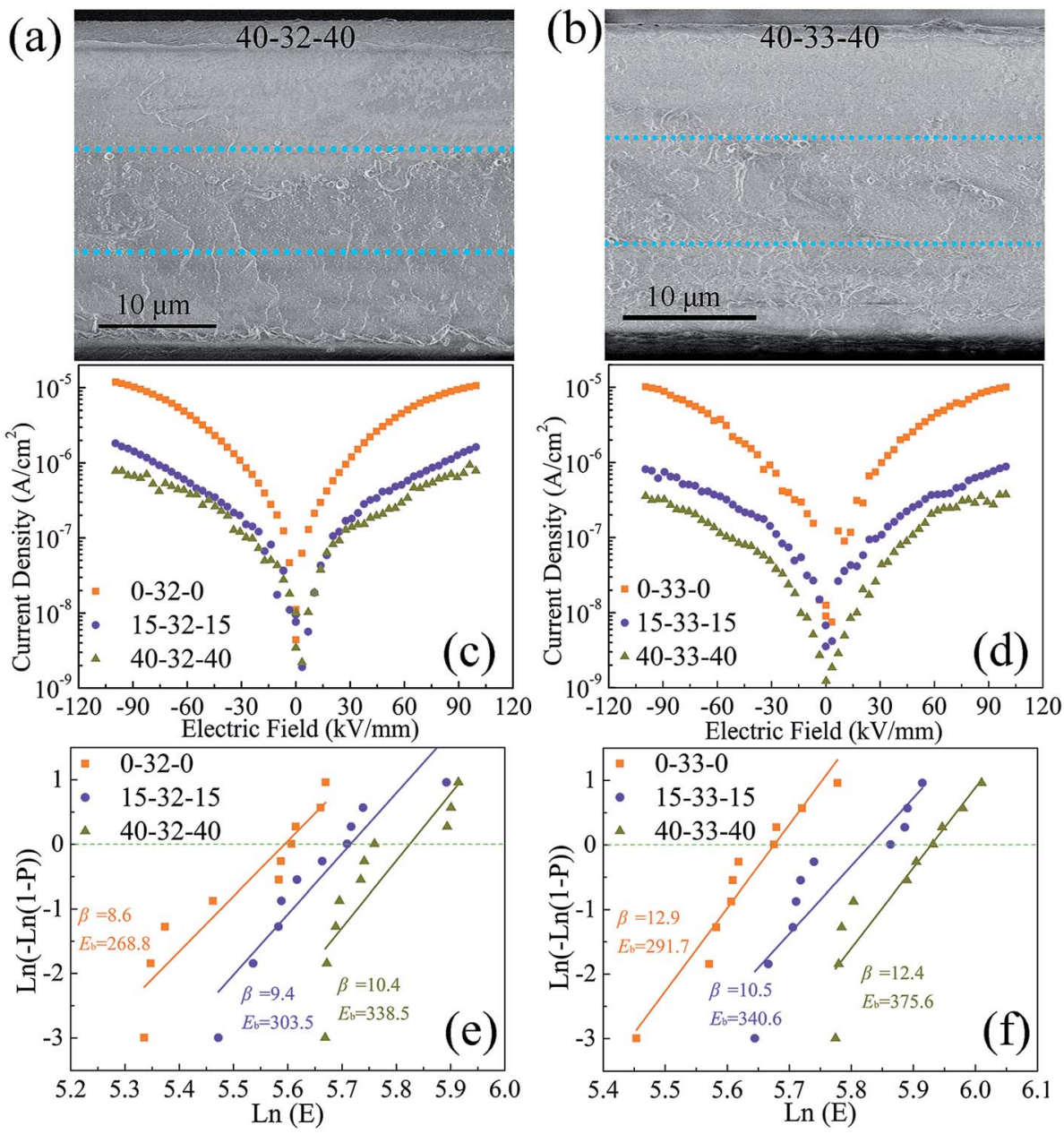

Fig. 7 Cross-sectional SEM microscopy ( $a$ and b), current density (c and d), Weibull distribution (e and f) of sandwich structure composites.

the middle layer. Such results are related to the introduction of linear PMMA and the core-shell structure of $\mathrm{BCZT}+\mathrm{Ag} @ \mathrm{Al}_{2} \mathrm{O}_{3}$.

Due to the difference in the dielectric constant between the composite layer $\left(\varepsilon_{\mathrm{c}}\right)$ and the polymer layer $\left(\varepsilon_{\mathrm{p}}\right)$ in the sandwich structure, the electric field will be redistributed between the different layers. The relationship between the electric field of the composite film $\left(E_{\mathrm{c}}\right)$ and that of the outer polymer film $\left(E_{\mathrm{p}}\right)$ can be derived from the series capacitor model, as eqn (3). ${ }^{37}$

$$
E_{\mathrm{c}} \times \varepsilon_{\mathrm{c}}=E_{\mathrm{p}} \times \varepsilon_{\mathrm{p}}
$$

According to the above equation, when the sandwich structure composites are subjected to an electric field, the polymer layer will withstand a higher electric field because it has a lower dielectric constant. The polymer layer itself has a higher breakdown strength, especially the polymer containing PMMA, and the middle layer having a higher dielectric constant will be subjected to a lower electric field. However, the outer layer can protect the middle layer from premature breakdown. ${ }^{37}$ In addition, it has been found in previous studies that the interfaces between the layers in the sandwich structure have an effect on preventing the development of the electric branch, which is one of the reasons the sandwich structure has a high breakdown strength. ${ }^{23,38-40}$ As expected, when the middle layer is the same, the sandwich-structure composite with 40\% PMMA/ PVDF as the outer layer has a high breakdown strength. When the outer layer is the same, the breakdown strength of the sandwich-structure composites with $\mathrm{BCZT}+\mathrm{Ag} @ \mathrm{Al}_{2} \mathrm{O}_{3} / \mathrm{PVDF}$ as the middle layer is higher.

Fig. 8 shows the $D_{\max }, D_{\mathrm{r}}$, energy density and efficiency of sandwich structure composites. At the same applied electric field, when the outer layer is the same the sandwich structure composites with BCZT $+\mathrm{Ag} / \mathrm{PVDF}$ as the middle layer show higher $D_{\max }$ (attributed to the larger dielectric constant of the middle layer) and $D_{\mathrm{r}}$ (attributed to the larger dielectric loss and conductivity of the middle layer). When the same middle layer is chosen at the same electric field, the sandwich structure composites with PVDF as the outer layer have the highest $D_{\max }$ and $D_{\mathrm{r}}$, which is attributed to the larger dielectric constant, dielectric loss and conductivity. In contrast, the sandwich structure composites with PMMA/PVDF as the outer layer have lower $D_{\max }$ and $D_{\mathrm{r}}$. However, the high $D_{\mathrm{r}}$ reduces the discharge energy density and efficiency. For instance, at $260 \mathrm{kV} \mathrm{mm}^{-1}$, the 0-32-0 composite has the highest $D_{\max }\left(7.37 \mu \mathrm{C} \mathrm{cm}{ }^{-3}\right)$ and $D_{\mathrm{r}}$ $\left(2.22 \mu \mathrm{C} \mathrm{cm}^{-3}\right)$, which results in its efficiency being only $48.0 \%$. 

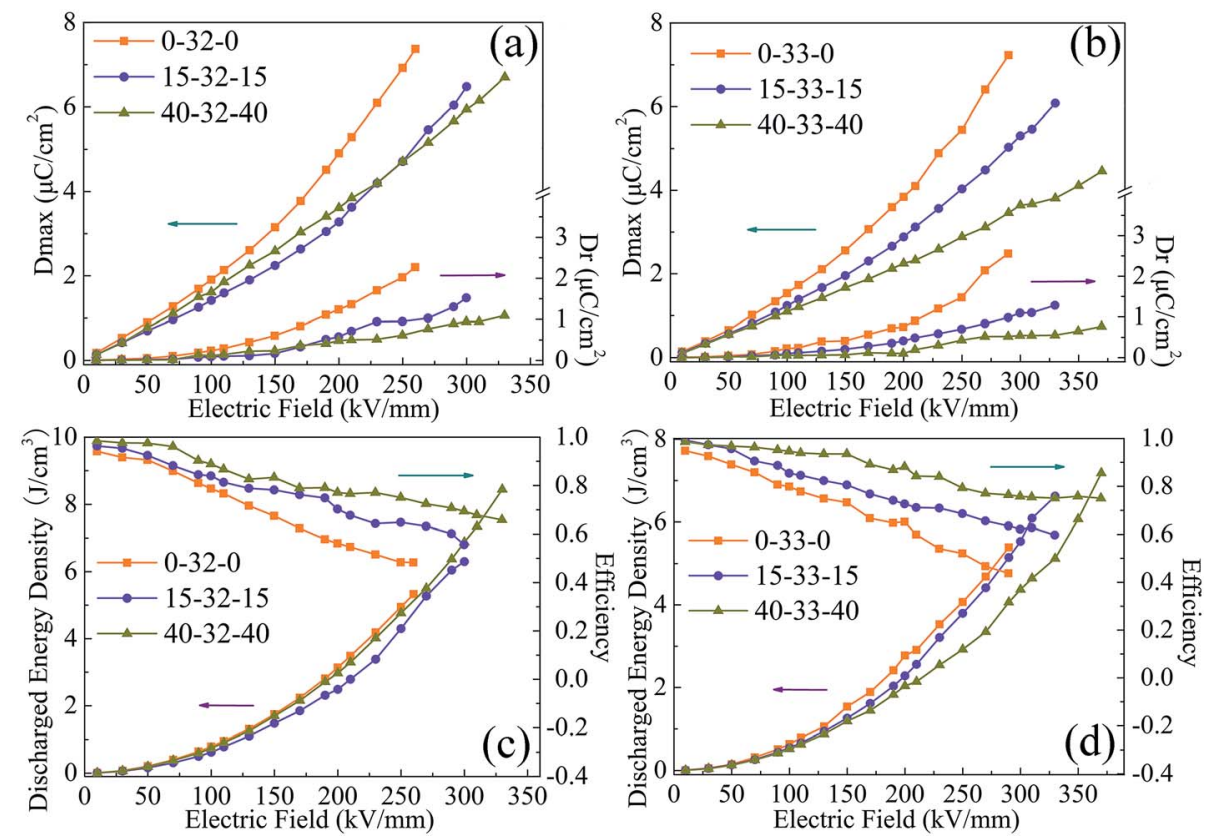

Fig. 8 Maximum polarization $\left(D_{\max }\right)$ and remnant polarization $\left(D_{\mathrm{r}}\right)$ (a and b), energy density and efficiency (c and d) of composite films with the sandwich structure.

It is worth noting that when the content of PMMA in the polymer outer layer is less than $40 \%$, the sandwich structure composites with $\mathrm{BCZT}+\mathrm{Ag} @ \mathrm{Al}_{2} \mathrm{O}_{3} / \mathrm{PVDF}$ as the middle layer have higher energy density because it can be polarized at a higher field strength. Although the 40-32-40 composite has the highest energy density $\left(U=8.48 \mathrm{~J} \mathrm{~cm}^{-3}, \eta=65.9 \%\right.$ at $330 \mathrm{kV}$ $\mathrm{mm}^{-1}$ ) of all sandwich-structure composites, 40-33-40 not only has a similar energy density to $40-32-40$ but also has the highest efficiency $\left(U=7.23 \mathrm{~J} \mathrm{~cm}^{-3}, \eta=75.8 \%\right.$ at $\left.370 \mathrm{kV} \mathrm{mm}^{-1}\right)$. In summary, the polymer outer layer with a high content of PMMA can improve the breakdown strength and efficiency of the composite while reducing its polarization. The performance of composites as the middle layer has an important influence on the energy density of sandwich composites.

\section{Conclusions}

Novel core-shell structure fillers consisting of BCZT, Ag and $\mathrm{Al}_{2} \mathrm{O}_{3}$ were fabricated by electrospinning. For the sandwich structure composites where the outer layer is the polymer layer and the middle layer is the composite, there is a higher breakdown strength, endowing sandwich-structure composites with much higher energy density and efficiency; the 40-33-40 composite has the energy density of $7.23 \mathrm{~J} \mathrm{~cm}^{-3}$ and efficiency above $75.8 \%$ at $370 \mathrm{kV} \mathrm{m}^{-1}$. This study provides a new strategy for fabricating sandwich-structure composites with lower dielectric loss, conductivity and current density, and improved breakdown strength, energy density and efficiency.

\section{Conflicts of interest}

The authors declare that they have no conflict of interest.

\section{Acknowledgements}

This research was funded by National Natural Science Foundation of China (No. 51977050, 51807042, 51807041), Natural Science Foundation of Heilongjiang Province of China (No. TD2019E002), Fundamental Research Foundation for Universities of Heilongjiang Province (No. LGYC2018TD001, LGYC2018JC020).

\section{References}

1 M. S. Whittingham, MRS Bull., 2008, 33, 411-419.

2 Y. F. Wang, L. X. Wang, Q. B. Yuan, J. Chen, Y. J. Niu, X. W. Xu, Y. T. Cheng, B. Yao, Q. Wang and H. Wang, Nano Energy, 2017, 44, 364-370.

3 X. Huang and P. Jiang, Adv. Mater., 27, 546-554.

4 Z. B. Pan, L. M. Yao, G. L. Ge, B. Shen and J. W. Zhai, J. Mater. Chem. A, 2018, 6, 14614-14622.

5 Z. Yao, Z. Song, H. Hao, Z. Yu, M. Cao, S. Zhang, M. T. Lanagan and H. Liu, Adv. Mater., 2017, 29, 1601727.

6 Z. B. Pan, L. M. Yao, J. W. Zhai, K. Yang, B. Shen and H. T. Wang, ACS Sustainable Chem. Eng., 2017, 5, 4707-4717. 7 S. Wu, W. P. Li, M. R. Lin, Q. Burlingame, Q. Chen and A. Payzant, Adv. Mater., 2013, 25, 1734-1738.

8 S. Wu, M. R. Lin, Q. Burlingame and Q. M. Zhang, Appl. Phys. Lett., 2014, 104, 072903.

9 Y. Feng, W. L. Li, Y. F. Hou, Y. Yu, W. P. Cao, T. D. Zhang and W. D. Fei, J. Mater. Chem. C, 2015, 3, 1250-1260.

10 B. C. Luo, X. H. Wang, Y. P. Wang and L. T. Li, J. Mater. Chem. A, 2014, 2, 510-519. 
11 Y. F. Feng, B. Miao, H. H. Gong, Y. C. Xie, X. Y. Wei and Z. C. Zhang, ACS Appl. Mater. Interfaces, 2016, 8, 1905419065.

12 Z. B. Pan, L. M. Yao, J. W. Zhai, B. Shen, S. H. Liu, H. T. Wang and J. H. Liu, J. Mater. Chem. A, 2016, 4, 13259-13264.

13 X. Y. Huo, W. P. Li, J. J. Zhu, Y. Li, L. H. Lou and Y. J. Zhu, J. Phys. Chem. C, 2016, 119, 25786-25791.

14 S. B. Luo, S. H. Yu, R. Sun and C. P. Wong, ACS Appl. Mater. Interfaces, 2014, 6, 176-182.

15 S. H. Liu, S. X. Xue, W. Q. Zhang, J. W. Zhai and G. H. Chen, J. Mater. Chem. A, 2014, 2, 18040-18046.

16 Z. M. Dang, M. S. Zheng and J. W. Zha, Small, 2016, 12, 16881701.

17 D. Guo, K. Cai and Y. L. Wang, J. Mater. Chem. C, 2017, 5, 2531-2541.

18 P. H. Hu, Z. Y. Jia, Z. H. Shen, P. Wang and X. R. Liu, Appl. Surf. Sci., 2018, 441, 824-831.

19 Y. C. Xie, Y. Y. Yu, Y. F. Feng, W. R. Jiang and Z. C. Zhang, ACS Appl. Mater. Interfaces, 2017, 9, 2995-3005.

20 R. Guo, H. Luo, W. W. Liu, X. F. Zhou, L. Tang, K. C. Zhou and D. Zhang, Phys. Chem. Chem. Phys., 2018, 20, 1803118037.

21 Z. B. Pan, L. M. Yao, J. W. Zhai, D. Z. Fu, B. Sheng and H. T. Wang, ACS Appl. Mater. Interfaces, 2017, 9, 4024-4033.

22 Z. B. Pan, Z. B. Pan, J. J. Liu, X. Y. Liu, F. P. Pi, J. W. Chen, B. Shen and J. W. Zhai, J. Mater. Chem. C, 2019, 7, 405-413.

23 Y. F. Wang, J. Chen, Y. Li, Y. J. Niu, Q. Wang and H. Wang, J. Mater. Chem. A, 2019, 7, 2965-2980.

24 P. H. Hu, Y. Shen, Y. H. Guan, X. H. Zhang, Y. H. Lin and Q. M. Zhang, Adv. Funct. Mater., 2014, 24, 3172-3178.

25 Q. Chi, T. Ma, Y. Zhang, Q. G. Chen, C. H. Zhang, Y. Cui, T. D. Zhang, J. Q. Lin, X. Wang and Q. Q. Lei, ACS Sustainable Chem. Eng., 2017, 6, 403-412.
26 Q. Li, L. Chen, M. R. Gadinski, S. H. Zhang, G. Z. Zhang, H. U. Li, E. Iagodkine, A. Haque, L. Q. Chen, T. N. Jackson and Q. Wang, Nature, 2015, 523, 576-579.

27 Q. G. Chi, T. Ma, Y. Zhang, Y. Cui, C. H. Zhang, J. Q. Lin, X. Wang and Q. Q. Lei, J. Mater. Chem. A, 2017, 5, 1675716766.

28 X. H. Xia, J. Zeng, L. K. Oetjen, Q. G. Li and Y. N. Xia, J. Am. Chem. Soc., 2012, 134, 1793-1801.

29 Y. Cui, T. D. Zhang, Y. Feng, C. H. Zhang, Q. G. Chi, Y. Q. Zhang, Q. G. Che, X. Wang and Q. Q. Lei, Composites, Part B, 2019, 177, 107429.

30 B. C. Luo, X. H. Wang, H. X. Wang, Z. M. Cai and L. T. Li, Compos. Sci. Technol., 2017, 151, 94-103.

31 E. Y. Shin, H. J. Cho, S. Jung, C. Yang and Y. Y. Noh, Adv. Funct. Mater., 2017, 28, 1704780.

32 Y. Shen, D. S. Shen, X. Zhang, J. Y. Jiang, Z. K. Dan, Y. Song, Y. H. Lin, M. Li and C. W. Nan, J. Mater. Chem. A, 2016, 4, 8359-8365.

33 M. Samet, V. Levchenko, G. Boiteux, G. Seytre, A. Kallel and A. Serghei, J. Chem. Phys., 2015, 142, 2027-2037.

34 D. Kang, G. Y. Wang, Y. H. Huang, P. K. Jiang and X. Y. Huang, ACS Appl. Mater. Interfaces, 2018, 10, 4077-4085. 35 Z. Zhou, J. Carr, M. Mackey, K. Z. Yin, D. Schuele, L. Zhu and E. Baer, J. Polym. Sci., Part B: Polym. Phys., 2013, 51, 978-991. 36 P. H. Hu, J. J. Wang, Y. Shen, Y. H. Guang, Y. H. Lin and C. W. Nan, J. Mater. Chem. A, 2013, 1, 12321-12326.

37 Y. Wang, Y. Hou and Y. Deng, Compos. Sci. Technol., 2017, 145, 71-77.

38 W. W. Nian, Z. Wang, T. Wang, Y. J. Xiao and H. N. Chen, Ceram. Int., 2018, 44, S50-S53.

39 Y. F. Wang, J. Cui, Q. B. Yuan, Y. J. Niu, Y. Y. Bai and H. Wang, Adv. Mater., 2015, 27, 6658-6666.

40 L. Yao, D. R. Wang, P. H. Hu, B. Z. Han and Z. M. Dang, Adv. Mater. Interfaces, 2016, 3, 1600016. 